\title{
ELEMENTOS FUNDAMENTAIS DA COSMOLOGIA DE GIORDANO BRUNO
}

\author{
Ideusa Celestino Lopes ${ }^{1}$
}

\begin{abstract}
Resumo:
Giordano Bruno (1548-1600), filósofo italiano que tratou de temas que ainda não eram considerados relevantes na segunda metade do século, em particular a temática cosmológica, que ainda não estava em crise. $\mathrm{O}$ geocentrismo aristotélico-ptolomaico era aceito de modo incondicional no ambiente acadêmico, não havia um debate explícito em torno da descrição do mundo. Ao tratar do tema cosmológico Bruno introduz a tese do heliocentrismo copernicano, como referência, para se contrapor ao modelo geocêntrico aristotélico-ptolomaico. A temática cosmológica perpassa de certo modo o conjunto da sua obra, desde os primeiros escritos como o texto A ceia de cinzas, publicada em 1582 escrito em italiano, considerado como sendo a obra que introduz a questão; até um dos últimos textos, L'immenso e gli innumerevoli publicado em 1591, em latim e desse modo dirigido ao ambiente acadêmico. O modelo cosmológico bruniano apesar de fazer referência a Copérnico, ao incorporar a tese de que a Terra não está no centro do universo, mas o Sol, não pode ser considerado um copernicano pois defende o universo como sendo infinito e povoado de inumeráveis mundos, desconsiderando também a ideia de centro. Descrições que não são tratadas por Copérnico. Para justificar a sua concepção de mundo e de universo, Bruno elabora uma discussão sobre os princípios aristotélicos, matéria e forma, com o intuito de apresentar uma nova base a partir da qual a natureza seja compreendida e que possa sustentar a tese de que o universo é infinito e povoado de inumeráveis mundos.
\end{abstract}

Palavras-chave: Geocentrismo. Crítica. Heliocentrismo. Princípios.

\section{FUNDAMENTAL ELEMENTS OF THE COSMOLOGY OF GIORDANO BRUNO}

Giordano Bruno (1548-1600) wasn an Italian philosopher who dealt in subjects that were not yet considered relevant in the second half of the century, in particular the cosmological theme, which was not in crisis already. AristotelianPtolemaic geocentrism was unconditionally accepted in the academic environment, there was no explicit debate about the description of the world. In dealing with the cosmological theme Bruno introduces the Copernican heliocentrism thesis, as a reference, to oppose the Aristotelian-Ptolemaic geocentric model. The cosmological theme permeates his body of work, from the earliest writings like The Supper of Ashes, published in 1582 written in Italian, considered to be the work that introduces the question; until one of the last texts, L'immenso e gli innumerevoli published in 1591, in Latin and thus directed to the academic environment. Bruno's cosmological model, although referring to Copernicus, incorporating the thesis that the Earth is not at the center of the universe but the Sun, can not be considered Copernican because it defends the universe as being infinite and populated by innumerable worlds, also disregarding the idea of a center, descriptions that are not dealt with by Copernicus. In order to justify his conception of the world and of the universe, Bruno elaborates a discussion on the Aristotelian principles, matter and form, intending to present a new base from by which the nature is understood and that can support the thesis that the universe is infinite and populated with innumerable worlds.

Keywords: Geocentrism. Critical. Heliocentrism. Principles.

\footnotetext{
${ }^{1}$ Prof. $^{\text {a }}$ Dr. ${ }^{a}$ Universidade Estadual Vale do Acaraú - UVA. E-mail: ideusalopes@gmail.com
} 


\section{Ideusa Celestino Lopes}

\section{Introdução}

Giordano Bruno, um pensador italiano ainda pouco estudado no nosso ambiente acadêmico, de um modo geral. Do conjunto das obras publicadas, em torno de trinta títulos, apenas quatro textos estão traduzidos para o português. Nesse ambiente escasso de material para pesquisa, deve-se acrescentar outro dado, o número reduzido de artigos publicados sobre o pensamento bruniano.

Neste artigo nos atemos à temática cosmológica, argumento que perpassa quase todos os textos brunianos. Ao colocar em discussão esse tema, Bruno dialoga com os aristotélicos do seu tempo que defendem a descrição do universo como sendo finito, geocêntrico. Desde os seus primeiros escritos, Bruno se colocou como crítico dessa concepção. Sempre defendeu a tese de que o universo é infinito e povoado de inumeráveis mundos. Nos propomos, assim, a apresentar os elementos que constitui esse novo modo de conceber o universo, com o intuito de oferecer um material que possa ser utilizado pelos pesquisadores que estão iniciando estudos sobre Bruno.

\section{Bruno e os aristotélicos}

Os ambientes da corte francesa e inglesa foram referências importantes para Bruno, após sair do convento dominicano em Nápoles². Em ambas as cortes, existiam espaços para exposição de ideias consideradas pouco ortodoxas pelo ambiente acadêmico. Porém, isso não significa dizer que todos eram partidários delas, mas apenas que havia uma maior tolerância e, podemos acrescentar, curiosidade pelo diferente e pelo exótico. As ideias de Bruno se enquadravam nesse perfil.

No período de permanência entre as duas cortes, que ocorre entre os anos de 1581 e 1586 Bruno publicou boa parte dos seus títulos. Somente no ano de 1584 publicou as seguintes obras: A ceia de cinzas; A causa, o princípio e o uno e Sobre o infinito, o universo e os mundos. Esses são textos nos quais Bruno apresenta e discute o tema cosmológico a partir da polarização entre a descrição do universo como sendo geocêntrica ou heliocêntrica. Os referidos textos trazem também uma forte crítica ao ambiente acadêmico de sua época, predominantemente aristotélico.

A crítica bruniana ao ambiente acadêmico se apoia na justificativa de as universidades difundirem, de modo dogmático as ideias de Aristóteles, impedindo desta forma, novas abordagens, em particular no tocante à filosofia da natureza. Segundo Bruno, os intelectuais recusavam-se a

2 Sugerimos os seguintes textos para um aprofundamento da trajetória bruniana, tanto pessoal como acadêmica: LOPES, 2013; CILIBERTO, 2009 e RICCI, 2000.

\begin{tabular}{|l|l|l|l|l|}
\hline Q Ronista Qialectus & Ano 5 & n. 12 & Janeiro - Julho 2018 & p. 314-326 \\
\hline
\end{tabular}


fazer uma análise crítica da filosofia aristotélica, mesmo diante de evidências fortes, como as apresentadas por Nicolau Copérnico (1573-1543) na obra As revoluções dos orbes celestes, na qual apresenta uma nova conformação astronômica para o universo, com o Sol no centro e a Terra girando em torno dele.

Na França, o ambiente da Sorbonne era prevalentemente aristotélico. Já o Collège de Cambrai e o Collège de Tréguier eram mais flexíveis, inclusive Bruno foi aceito no Collège de Cambrai como leitor extraordinário de filosofia no primeiro período que esteve em Paris, no período de 1581 a 1583 . Em Oxford, no entanto, não teve uma experiência bem-sucedida ${ }^{3}$. As impressões sobre o referido ambiente, e em particular sobre os professores que assumiam uma postura aristotélica, são apresentadas em algumas passagens na obra A ceia de cinzas, publicada em Londres.

\section{A temática cosmológica}

A obra A ceia de cinzas tem como referência o heliocentrismo copernicano, mas Bruno não faz uma defesa incondicional do copernicanismo, apesar de ter sido um dos primeiros a defendê-lo publicamente. No entanto, apresenta uma descrição do universo que ultrapassa os limites do heliocentrismo copernicaco, ao defender o universo como sendo infinito e povoado de inumeráveis mundos. O título, já em si é provocador, pois traduz uma evidente implicação religiosa. Uma interpretação possível diz respeito ao caráter da quarta-feira de cinzas ser considerada pelos católicos, como sendo o início de um período de reflexão, de penitência, com o intuito de deixar os erros para trás a fim de que recordem, em particular, da efêmera fragilidade da vida humana. Bruno não tratou do tema da morte física, mas o relacionou à morte de um modo de descrever a estrutura cósmica: o geocentrismo. Os dois penitentes do jantar seriam representados pelos professores da universidade de Oxford, Nundinio e Torquato.

A causa, o princípio e o uno, texto que mais despertou o interesse pelo pensamento bruniano nos anos que sucederam à sua morte, principalmente nos ambientes em que dominava o romantismo e o idealismo alemão, que o consideravam como sendo o de fundação da filosofia nolana ${ }^{4}$. O título pode, num primeiro momento, indicar que será feita uma abordagem exclusivamente teológica, mas Bruno continua no seu projeto de apresentar uma nova cosmologia. Nesse sentido, ele apresenta uma concepção geral sobre a filosofia da natureza, partindo do pressuposto de que o conhecimento do primeiro princípio e da causa de todas as coisas, Deus, não é

Sobre o referido tema ver o texto de AQUILECCHIA, 1993.

4 Cf. CANONE, 2000, p. 219.

\begin{tabular}{|l|l|l|l|l|}
\hline Qenista Qialectus & Ano 5 & n. 12 & Janeiro - Julho 2018 & p. 314-326 \\
\hline
\end{tabular}


possível em si mesma, mas através do seu vestígio, que é a própria natureza, entendida como grande animal e simulacro do primeiro princípio. Ou seja, para Bruno, Deus não pode ser objeto de conhecimento direto, mas somente através dos seus vestígios ou por meio da negação, pois Ele é incomensurável. O universo, sendo o efeito, o visível da comunicação de Deus com a natureza, pode ser estudado e compreendido.

Bruno entende a causa eficiente como intelecto universal, a qual, no entanto, não é pensada somente como sendo externa às coisas, mas também intrínseca a toda realidade. Nesse sentido, a natureza seria perpassada e animada pela alma, pelo espírito, que está em todas as coisas.

Na sequência de publicações temos: Sobre o infinito, o universo e os mundos, texto que apresenta de forma explícita o debate entre a cosmologia infinitista e a finitista. Bruno apoia a sua teoria da infinitude do universo sobre a tese da absoluta coincidência entre Deus e vontade, entre potência e ato. Causa primeira infinita tem como efeito o infinito, sendo este o fio condutor da discussão. Nesse texto, expõe a configuração teórica de sua cosmologia, que concebe o universo como sendo infinito e povoado de inumeráveis mundos.

Nessas três obras elencadas, Aristóteles é o interlocutor principal. A discussão cosmológica para Bruno passa necessariamente pelo debate direto com o Estagirita e os seus seguidores, que continuam a defender o geocentrismo nos ambientes acadêmicos.

Além desses títulos podemos acrescentar outras três obras que também tratam do tema cosmológico: Centoventi articoli sulla natura e sull'universo contro i peripatetici (Paris, 1586); Acrotismo Cameracense - le spiegazioni degli articoli di fisica contro i peripatetici (Wittenberg, 1588) e L'immenso e gli innumerevoli (Frankfurt, 1590).

Enquanto que as obras citadas anteriormente foram escritas em italiano, no formato de diálogo, estas últimas foram redigidas em latim, expondo os seus argumentos cosmológicos de modo mais sistemático ${ }^{5}$. No entanto, reforça argumentos já tratados nos diálogos italianos, como a polêmica contra a física aristotélica ou sobre a infinitude do universo.

O L'immenso é considerado um texto que tinha como alvo o ambiente acadêmico de sua época, cujos integrantes provavelmente não tinham lido os diálogos escritos em italiano. Tanto o L'immenso como o Camoeracensis Acrotismus, segundo Granada, são abordagens dirigidas de modo particular aos astrônomos, com o intuito de "encontrar entre os astrônomos a confirmação da verdade de sua própria cosmologia (bruniana)", (GRANADA, 1996, p. 16).

Nessas obras, Bruno apresentou de modo exaustivo a sua crítica à cosmologia tradicional e a defesa de uma nova concepção cosmológica. Segundo Aquilecchia A Ceia de cinzas

5 Cf. a argumentação de Aquilecchia sobre o uso da língua vulgar nos textos brunianos em L'adozione del volgare nei dialoghi londinesi di Giordano Bruno in: AQUILECCHIA, 1993.

\begin{tabular}{|c|c|c|c|c|}
\hline Q Rovista Dialeatus & Ano 5 & n. 12 & Janeiro - Julho 2018 & p. $314-326$ \\
\hline
\end{tabular}


pode ser considerada como uma "introdução" à referida temática; e os outros três textos apresentariam os fundamentos teóricos da filosofia nolana ${ }^{6}$.

Bruno elenca entre os principais erros da filosofia da natureza aristotélica os seguintes aspectos: o geocentrismo, a esfera das estrelas fixas, a teoria do "lugar natural" e a hierarquia dos elementos celestes. Essa representação dos corpos celestes e da estrutura do universo foi pensada, segundo o nolano, em virtude do modo equivocado com que Aristóteles desenvolveu a discussão sobre os princípios que constituem a natureza.

Segundo Bruno, Aristóteles distingue na natureza dois princípios, matéria e forma, identificados como potência e ato, respectivamente, mas privilegia a forma em detrimento da matéria, a partir do qual o movimento é concebido. Ou seja, chama de natureza seja a matéria seja a forma, mas salienta que a forma é mais apta a definir a natureza enquanto ato para o qual tende o movimento. $\mathrm{O}$ erro, portanto, da filosofia aristotélica estaria apoiado no antagonismo estabelecido entre forma e matéria, entre ato e potência. Essa discussão vai ser desenvolvida na obra A causa, $o$ princípio e o uno. A sua intenção é refutar a distinção aristotélica referente à matéria, ao considerála como sendo potência pura, nua, sem ato, sem virtude e perfeição e, portanto, dependente da forma. Bruno defende que a matéria é plena, pois possui de modo implicato todas as formas e atualizações, isto é, possui toda a natureza em substância. Ele considera ainda que a matéria é mais digna do nome de natureza, pois a matéria é imutável, no sentido que não se torna algo diverso do que é, pois já tem em si mesma toda a diversidade. A matéria é sempre a mesma, por isso não se pode associá-la à imperfeição.

Não obstante, a cosmologia bruniana parte, de um ponto comum com a filosofia aristotélica, ou seja, o de que a física, a filosofia da natureza, tem como objeto de estudo o conhecimento dos princípios naturais, não sendo, portanto, apenas produtora de descrições sobre os fenômenos, mas se impõe também como um estudo dos princípios que a regem. Esse é um ponto temático em que Bruno segue Aristóteles, pois o nolano concebe a natureza a partir do postulado aristotélico, qual seja: "me refiro àquela natureza que para Aristóteles é o princípio de todo o movimento e que é substância daquilo que admite em si mesmo o princípio de movimento"7.

Parece paradoxal, após afirmarmos que Bruno é um crítico radical de Aristóteles, acrescentar que o ponto de partida para discutir a natureza é o mesmo do Estagirita, ou seja, que a natureza somente pode ser pensada a partir dos princípios que a constituem. Entretanto, apesar de Bruno afirmar que compartilha do mesmo ponto de partida aristotélico, ele não o segue

Cf. a introdução de Aquilecchia ao texto La cena delle cenere, in: AQUILECCHIA, 1993.

BRUNO, 2009, p. 65, "mi riferisco a quella natura che per Aristotele è il principio di ogni movimento e che è sostanza di ciò che ammette in se stesso il principio di movimento".

\begin{tabular}{|c|c|c|c|}
\hline Q Rovista Dialectus & Ano 5 & n. 12 & Janeiro - Julho 2018 \\
\hline
\end{tabular}


prontamente, haja vista que Aristóteles se refere à natureza como sendo "princípio e causa do ser em movimento e do estar em repouso da qual esta pertence originariamente, por si mesma e não de modo acidental" ${ }^{\prime 8}$. O conceito de natureza utilizado por Bruno deve ser entendido como referente à natureza como matéria. Desse modo, trata-se de uma concepção específica de natureza que se distingue da definição aristotélica em que a mesma é concebida em sua amplitude ontológicometafísica. Ademais, sua intenção é excluir a exigência de um princípio formal que determine o movimento. Nesse sentido, na discussão sobre a natureza, Bruno se detém sobre o conceito de matéria.

Por conseguinte, a natureza é concebida, segundo Bruno, como sendo constituída por princípios, mas com funções diversas das estabelecidas por Aristóteles. Neste sentido, segundo Bruno, o erro aristotélico estava entre outras coisas assentado na ideia de que a forma determinaria a matéria. Para Bruno, não existem dois princípios, matéria e forma, que determinariam a natureza, mas apenas um, a matéria, já que a forma é sua parte constitutiva, não existindo separado desta. A forma não é concebida como princípio de movimento para o qual tende a matéria. Ao contrário, a matéria é o princípio de geração e corrupção e, portanto, princípio de todo o movimento. Assim, a matéria seria mais digna de ser denominada de princípio, pois possui os requisitos de permanência, imobilidade e universalidade. Neste sentido, a argumentação bruniana se concentra na defesa da matéria como uma "potência grávida" que contém em si todas as formas e atualizações, não havendo uma determinação da forma na matéria, mas a matéria já seria "grávida" de toda determinação. Desse modo, a forma deve ser pensada como inerente à matéria, sem a qual aquela não existiria, e só tem existência na matéria, não sendo a ela exterior ou independente.

Apesar de a análise sobre a natureza empreendida por Bruno ter como referência o pensamento aristotélico, convém fazer uma inserção sobre o alcance e a profundidade do antiaristotelismo de Bruno. Segundo Amato, a proximidade com Aristóteles não é suficiente para considerar Bruno um aristotélico, pois as suas premissas e conclusões são incompatíveis com as do sistema filosófico aristotélico ${ }^{9}$. Eis um exemplo: a forma, que exercia uma função transcendente ao determinar a matéria, resquício do pensamento platônico, é pensada como imanente no pensamento bruniano, sendo concebida, ainda, como constituinte da matéria, sem a qual não existiria. Assim, a ideia bruniana acerca da natureza se contrapõe à noção aristotélica de que a forma possui status de princípio e adquire predominância em relação à matéria, determinando-a. Nesse sentido, apesar de Bruno considerar a indagação sobre os princípios da natureza como ponto de partida para construir

8 ARISTOTELE, 2007, Livro II, 129b, "principio e causa dell'essere in movimento e dello stare in riposo di ciò cui essa appartiene originariamente, per sé stessa e non in modo accidentale".

9 Cf. a análise de AMATO, 2005.

\begin{tabular}{|l|l|l|l|l|}
\hline Qevista Qialectus & Ano 5 & n. 12 & Janeiro - Julho 2018 & p. 314-326 \\
\hline
\end{tabular}


seja uma física, seja uma metafísica, o modo de concebê-los não coincidem com o do modelo aristotélico.

Outro tema que os distinguem: o conceito de movimento. Aristóteles justifica o movimento como sendo a representação da passagem da potência ao ato, distinguindo então dois tipos de movimento: o retilíneo e o circular. O primeiro aparece como expressão da imperfeição; o segundo traduz a perfeição. Outra característica do movimento aristotélico: sua tendência ao repouso, ou seja, o retorno ao "lugar natural". Com esse esquema conceitual, Aristóteles justifica então a divisão do universo entre mundo lunar e sublunar. O mundo lunar é perfeito, pois o movimento desenvolvido pelos corpos que o compõem é circular. O mundo sublunar, por sua vez, é caracterizado pela imperfeição. O deslocamento retilíneo dos corpos para o alto ou para baixo é justificado pela composição dos quatro elementos que compõe o mundo sublunar: água, terra, ar e fogo.

Para Bruno, entretanto, o movimento só pode ser entendido como a eterna atualização da forma na matéria, pois a matéria é o que permanece inalterável. Nesse sentido, refuta o dualismo aristotélico que distingue entre o fora e o dentro do universo, entre o mundo lunar e o sublunar. A natureza concebida pelo nolano é homogênea, isto é, o mesmo processo que ocorre na Terra também é verificado nos outros corpos celestes, sem distinções.

Bruno concebe a matéria como sendo substância do movimento e princípio e fim último do mesmo. Nesse sentido, ele refuta a concepção aristotélica do movimento a partir do princípio teleológico do devir, que move tudo sem ser movido e para qual tende todo o movimento. O movimento, na concepção aristotélica, é concebido como sendo expressão de uma imperfeição que busca a perfeição, que ele define como sendo o repouso, o ato. Assim, o lugar natural das coisas é o repouso, pois os corpos tendem ao repouso, não ao movimento. Dessa forma, Aristóteles explica a disposição dos quatro elementos (terra, água, ar e fogo), justificando que o seu movimento tem como fim o seu lugar natural: o repouso. O mundo sublunar é imperfeito em particular porque os seus elementos estão fora do seu lugar natural. O movimento existente na região lunar é diverso daquele da região sublunar, pois enquanto nesta há um deslocamento para uma condição ideal, na esfera lunar os corpos são constituídos de um elemento chamado éter, que é inalterável, puro e incorruptível. Aqui o movimento desenvolvido é o circular, perfeito, sem começo nem fím.

A concepção bruniana acerca da natureza tendo como princípio a matéria, em oposição ao modelo aristotélico, produz outra concepção de natureza, bem como de movimento. O movimento e a forma no modelo aristotélico estão intrinsecamente ligados, de modo que os corpos tendem para o seu lugar natural: o repouso e a perfeição. Enquanto isso, no pensamento bruniano, o

\begin{tabular}{|c|c|c|c|c|}
\hline Qovista Dialectus & Ano 5 & n. 12 & Janeiro - Julho 2018 & p. $314-326$ \\
\hline
\end{tabular}


movimento dos corpos não é compreendido como busca pela perfeição, pelo lugar natural, mas aparece impulsionado pelo "instinto" de autoconservação. Nesse sentido, para Bruno, a concepção equivocada dos princípios que constituem a natureza concebida por Aristóteles, sustentou a construção de um cosmo imaginário e privado de sentido. Essa é a base da abordagem bruniana acerca do cosmo, que fundamenta a sua crítica ao mundo considerado como finito, e a sua defesa de um universo infinito.

\section{Causa eficiente}

A partir da abordagem acerca dos princípios que constituem a natureza, na qual redimensiona a noção de matéria e desse modo a concepção de movimento, em particular a ideia de "lugar natural", Bruno também critica a concepção do divino como transcendente, pois, o que determinaria todo o movimento é a alma ou espírito, imanente no mundo. Eis por que, segundo ele, é inútil investigar a existência de um motor extrínseco. Ao refutar a existência de um motor externo que move o universo, Bruno interioriza o movimento a partir de um princípio vital interno, pois

é conveniente à comodidade das coisas que são, e ao efeito da perfeitíssima causa, que este moto seja natural de princípio interno, sem resistência. Isto convém a todos os corpos que sem contato sensível de outro impelente ou atraente se movam (BRUNO, 2007, p. 548).

A causa eficiente é entendida como sendo causa extrínseca e intrínseca, e sobre isso diz Bruno: "eu a chamo de causa extrínseca, porque, como eficiente, não é parte dos compostos e coisas produzidas, é causa intrínseca enquanto que não opera em volta da matéria nem fora dela" (BRUNO, 2007, p. 654). A causa intrínseca é identificada com a forma e, sendo assim, desaparece do vocabulário bruniano a noção de causa formal, pois ele a identifica como sendo o meio pelo qual a causa eficiente atua: "cada agente que opera de acordo com a regra intelectual, não procura agir se não segundo alguma intenção; e esta não é sem apreensão de alguma coisa; e esta não é outra que a forma da coisa que é o de produzir-se"(BRUNO, 2007, p. 654). Desse modo, distingue dois tipos de forma: uma através do qual a causa eficiente atua e a outra como princípio que, juntamente com a matéria, constitui o mundo.

Segundo Bruno, não há porque discutir a existência de um primeiro motor que tudo move sem ser movido, pois o movimento e o que o produz são infinitos e "a alma movente e o corpo movido concorrem num sujeito finito, isto é, em cada um destes astros mundanos" (BRUNO, 1978, p. 24). Para explicar o movimento dos corpos celestes, Bruno recorre a uma pluralidade de

\begin{tabular}{|c|c|c|c|c|}
\hline Qovista Dialectus & Ano 5 & n. 12 & Janeiro - Julho 2018 & p. $314-326$ \\
\hline
\end{tabular}


almas que movem os astros que compõem o universo ${ }^{10}$. O movimento é imanente, não é realizado a partir de algo fora do mundo, pois há um espírito original, comum, que percorre todo o universo e permite o movimento dos inumeráveis mundos. Desse modo, para Bruno,

tudo emana do suficiente princípio interior para o qual naturalmente vem a agitar-se com força, e não de princípio exterior como vemos sempre acontecer àquelas coisas que são movidas ou contra ou alheia à própria natureza (BRUNO, 2007, p. 512).

No cosmo bruniano, povoado de inumeráveis mundos, não existindo um centro específico, a trajetória dos seus elementos também se diferencia do cosmo tradicional, no qual os elementos eram considerdaos fixos em esferas que desenvolviam trajetórias circulares, com exceção da Terra que estava fixa no centro deste universo. Na concepção bruniana, não há esferas e o movimento dos corpos celestes é justificado pela existência de um princípio vital no qual "o princípio dos movimentos é intrínseco à própria natureza, à própria alma, à própria inteligência" (BRUNO, 2007, p. 548) ${ }^{11}$. O movimento dos corpos é aqui entendido como sendo realizado a partir de um elemento intrínseco ao próprio corpo: a alma. Com a ideia de princípio interno, Bruno pode desconsiderar a existência do primeiro motor aristotélico que tudo move sem ser movido, bem como a justificativa da oitava esfera, que desenvolveria uma trajetória circular perfeita e impulsionaria as demais ${ }^{12}$. A descrição aristotélica do movimento a partir de algo externo, segundo o nolano, faria com que o movimento dos astros se desse de modo violento e não natural. Em Aristóteles, os elementos são identificados como pertencendo a um lugar natural; eles tendem para esse lugar. Bruno critica tal concepção de lugar natural e defende a ideia de que todos os corpos se movem conforme uma exigência de sobrevivência, de manutenção da vida. A cosmologia bruniana propõe um abandono da noção de lugar natural e de movimento natural próprios da cosmologia aristotélica.

\section{Conclusão}

Segundo Bruno, a cosmologia aristotélica, que postulava um universo finito e hierarquizado, representou o início de um período de sombras para a humanidade. A partir desse referencial, Bruno estabelece uma conexão entre a descrição cosmológica e o curso da história da humanidade, que oscilaria entre luz e sombras. A luz é relacionada ao modo como a verdadeira cosmologia é tratada, em que a Terra não é compreendida como imóvel, mas inserida num universo

10 Para Bruno, os astros são como grandes animais e, portanto, também portadores de uma alma.

11 Aristóteles refuta a existência da alma como princípio que impulsiona o movimento, "se ne conclude che nessuno astro si muove di un movimento dovuto a un'anima", cf. De Caelo, 291 a.

12 Cf. ARISTOTELE, 2002, $291 \mathrm{~b}$.

\begin{tabular}{|l|l|l|l|l|}
\hline Qevista Dialectus & Ano 5 & n. 12 & Janeiro - Julho 2018 & p. 314-326 \\
\hline
\end{tabular}




\section{ELEMENTOS FUNDAMENTAIS DA COSMOLOGIA DE GIORDANO...}

Ideusa Celestino Lopes

homogêneo e ilimitado. Este modelo já se encontrava entre os "verdadeiros filósofos". Segundo Granada, o período de luz ao qual Aristóteles cobre de sombras, para Bruno, é o conhecimento que era oriundo do prisma teológica egípcia, caldeia, veterotestamentaria e grega incluindo Platão ${ }^{13}$. Neste sentido, a sua cosmologia não pretende ser de todo uma inovação, em oposição à cosmologia aristotélica, mas uma atualização de ideias já conhecidas. E, assim, ele nada estaria dizendo de absurdo, mas apenas algo contrário às "sombras" produzidas pelo aristotelismo. Deste modo, ao mesmo tempo em que declara a sua filosofia como verdadeira e nova, tem consciência que o novo só pode surgir do velho: "que não existe coisa nova, que não possa se tornar velha; e nem existe coisa velha, que não tenha sido nova um dia"(BRUNO, 2007, p. 460). Neste sentido, a originalidade é uma ilusão, pois nada é totalmente seu e nem totalmente novo, pois qualquer concepção para ser elaborada e comunicada precisa de um arcabouço já existente, de categorias e linguagem, às quais podemos fazer revisões no caminho da busca da verdade.

Apesar da carga crítica dos seus textos, Bruno adverte o leitor, explicitamente, no préfacio da obra Spaccio della bestia trionfante, que o seu objetivo não é subverter a ordem das coisas com o intuito de provocar o caos, mas libertar a humanidade da ignorância, das trevas, baseada na aceitação da descrição do universo como sendo finito, dividido entre o mundo divino e o mundo humano, entre a perfeição e a imperfeição. Para ele, a filosofia que defendia o mundo como sendo finito era muito mais prejudicial à religião e à sociedade do que a que propunha o universo como sendo infinito, pois esta última é uma representação verdadeira do mundo físico.

O universo descrito como infinito, não há como determinar um centro, sendo possível determiná-lo por toda parte. Assim, não há um dentro e um fora, um interno e um externo e, por isso, as posições podem se alternar, já que "todas as coisas na sua origem têm vicissitude de domínio e de servidão, felicidade e infelicidade, daquele estado que se chama vida e daquele que se chama morte, de luz e trevas, de bem e de mal" (BRUNO, 2007, p. 557).

Sendo o universo infinito e homogêneo, Bruno defende que não existiria distinção entre perfeito e imperfeito, nem centro nem periferia, e todos os entes naturais, tanto os terrestres como os celestes, possuiriam um idêntico grau de perfeição. Inviabilizando, assim, a divisão entre mundo sensível e mundo inteligível.

O mundo sensível é apresentado como simulacro do inteligível, isto é, trata-se de uma imagem do inteligível. Deus é o fundamento do mundo no próprio mundo e não fora dele. Ao negar que exista uma distinção entre mundo celeste e mundo sublunar, o cosmo passa a ser descrito a partir de outra estrutura, bem diversa da tradicional. O inteligível não está fora do mundo, mas faz

13 Cf. essa discussão em GRANADA, 1996, p. 18

\begin{tabular}{|c|c|c|c|c|}
\hline Qevista Dialectus & Ano 5 & n. 12 & Janeiro - Julho 2018 & p. $314-326$ \\
\hline
\end{tabular}


parte dele, pois não há uma separação entre o divino e a natureza. Esta é uma das consequências da sua cosmologia: a existência de uma relação direta entre o divino e a natureza.

Giordano Bruno, sem os instrumentos que poderiam provar a existência de inumeráveis mundos, faz a defesa dela através do argumento por assimilação, ou seja, "o espaço infinito possui aptidão infinita, e nesta infinita aptidão se louva o infinito ato de existência; pelo que o eficiente infinito não pode ser considerado deficiente, e a aptidão não é vã” (BRUNO, 2007, p. 44). Bruno reconhecesse que é difícil provar a tese da infinidade dos mundos, mas segundo a sua argumentação ela não traria "inconveniente algum, e até nos liberta de inúmeras angústias que nos envolvem se afirmarmos o contrário" (BRUNO, 2007, p. 44).

Consideramos que a adesão bruniana ao copernicanismo e ao radicalismo assumido frente ao próprio Copérnico, ao descrever o Cosmo como sendo infinito e povoado de inumeráveis mundos, não é balizada apenas pela discussão filosófica acerca do conceito de natureza, sobre os princípios que a compõem, mas é também profundamente marcada por um significado teológico. A descrição da estrutura do universo, é o que move Bruno na elaboração de uma nova cosmologia, entretanto, a sua discussão cosmológica não está separada de uma fundação ontológica, ou seja, a sua concepção de natureza é intrinsecamente ligada a uma visão de divino.

\section{REFERÊNCIAS}

AMATO, Barbara. Aspetti dell'antiaristotelismo bruniano nel Camoercensis Acrotismus. In: Bruniana \& Campanelliana, Pisa - Roma: Fabrizio Serra - editore XI, p. 143 - 165, luglio-2005.

AQUILECCHIA, G. Introduzione a La Cena de le Ceneri. In: Schede bruniane (1950 - 1991). Roma: Vecchiarelli Editore, 1993, p. 65-96.

L'adozione del volgare nei dialoghi londinesi di Giordano Bruno. In: Schede bruniane (1950 - 1991). Roma: Vecchiarelli Editore, 1993, p. 41-64.

ARISTOTELE. Fisica. A cura di Luigi Ruggiu. Milano: Mimesis, 2007.

Il Cielo. A Cura di Alberto Jori. Milano: Bompiano, 2002.

La metafisica. A cura di Carlo A. Viano. Torino: UTET Libreria, 1995.

\begin{tabular}{|l|l|l|l|l|}
\hline Qenista Dialectus & Ano 5 & n. 12 & Janeiro - Julho 2018 & p. 314-326 \\
\hline
\end{tabular}


CANONE, Eugenio. La cena de le ceneri e l'edificio della nolla filosofia. In: Paradigmi. Anno XVIII - Nuova serie - p. 217 - 235, Mag/Ago-2000.

CILIBERTO, Michele. Giordano Bruno - il teatro della vita. Milano: Arnoldo Mondadori Editore S.p. A., 2009.

BRUNO, Giordano. Acrotismo Camemacense - le spiegazioni degli articoli di fisica contro i peripatetici. A cura di Barbara Amato. Pisa - Roma: Fabrizio Serra - editore, 2009.

. La cena delle ceneri. In: Opere italiane. Torino: UTET Libreria, 2007, p. 425 - 571.2 v.

. De la causa, principio et uno. In: Opere italiane. Torino: UTET Libreria, 2007, p. 591 $746.2 \mathrm{v}$.

. De l'infinito, universo e mondi. In: Opere italiane. Torino: UTET Libreria, 2007, p. 07 $167.2 \mathrm{v}$.

. L'immenso e gli innumerevoli. In: Opere latine. A cura di Carlo Monti. 2. ed. Torino: Unione Tipografico-Editrice Torinense, 2000, p. 417 - 819.

. Sobre o infinito, o universo e os mundos. In: Os pensadores. Tradução de Aristides Lobo, 2. ed. São Paulo: Abril Cultural, 1978, p. 03 - 91.

DIELS, Hermann; KRANZ, Walther. I presocratici. A cura di Giovanni Reale. Milano: Bompiani, 2008.

GRANADA, M. Á. La reivindicación de la filosofia en Giordano Bruno. Barcelona: Herder, 2005.

LOPES, I.C. A cosmologia bruniana como um pressuposto para uma reforma moral. Tese de Doutorado. João Pessoa, UFPB, Departamento de Filosofia, 2013.

\begin{tabular}{|l|l|l|l|l|}
\hline Qenista Dialectus & Ano 5 & n. 12 & Janeiro - Julho 2018 & p. 314-326 \\
\hline
\end{tabular}


RICCI, Saverio. Giordano Bruno nell'europa del cinquecento. Roma: Salerno Editrice, 2000.

\begin{tabular}{|l|l|l|l|l|}
\hline Govista Qialectus & Ano 5 & n. 12 & Janeiro - Julho 2018 & p. 314-326 \\
\hline
\end{tabular}

